\title{
A Foot in the Door: Access to Asylum in South Africa
}

\author{
DARSHAN VIGNESWARAN
}

\begin{abstract}
Asylum seekers in South Africa experience extreme difficulties lodging their claims at the Department of Home Affairs. This paper utilizes new survey data to measure the extent of the Department's failures to provide access to the status determination process. The principal finding is that South African officials often go out of their way to prevent asylum seekers from entering the system. This provides support for the argument the Department is beholden to an institutional culture of immigration protectionism. This assessment differs from conventional analyses of poor African performance of status determination which emphasize issues of corruption and institutional capacity.
\end{abstract}

\section{Abstract}

Les demandeurs d'asile en Afrique du Sud rencontrent des difficultés extrêmes pour présenter leurs demandes au Département des affaires intérieures. Cet article utilise des données d'un nouveau sondage pour mesurer l'étendue des manquements du Département vis-à-vis de son devoir de rendre accessible le processus de détermination du statut. La conclusion principale est que les autorités Sud africaines sévertuent souvent pour empêcher les demandeurs d'asile d'accéder au système. Cela semble soutenir l'allégation que le Département est prisonnier d'une culture institutionnelle de protectionnisme en matière d'immigration. Cette évaluation se démarque des analyses conventionnelles de la mauvaise performance africaine en matière de détermination du statut qui, elles, soulignent des problèmes de corruption et de manque de capacité institutionnelle.
You get stepped on. You are tired, you are bored and thirsty.
You feel like you are dead and not human anymore.

\section{Introduction}

Responding to a perceived need to prevent unwanted migration since the 1980s, many developed countries have instituted measures to limit access to asylum. While status determination processes and procedures in Africa have usually departed significantly from "best (and worst) practices" in the Global North, countries on the continent have taken a similar turn towards more limited access. ${ }^{2}$ However, the provisions and procedures utilized by African states towards this end have differed from European, Asian, and North American counterparts. The main differences in developments on the continent need to be understood within the different body of international instruments which govern refugee protection, in particular the 1969 Organization of African Unity (OAU) Convention governing the Specific Aspects of the Refugee Problem in Africa (the OAU Convention). The Convention envisages a framework of protection that takes into account the unique character of refugee flows in the continent and the unique capabilities of African states, providing specifically for group based or prima facie determination systems. ${ }^{3}$ Despite these differences, status determination in Africa is not entirely different in character from counterparts elsewhere. While group based and UNHCR implemented determination systems are far more prominent across the region, status determination models in Africa often share important features with practices outside the continent. While it is unlikely that jurisprudence in non-African countries will ever afford much attention to African courts' interpretations of key provisions in the UN Refugee Convention, status determination issues in African countries will almost certainly impact upon developments and debates elsewhere, given the continent's disproportionate share of the world's refugee population. 
It is in this respect that the South African case is particularly interesting. South Africa is currently attempting to meet a relatively ambitious and recent set of refugee commitments. The transition to democratic rule and relative stability in the 1990s saw the end of an era in which the Republic was both an international pariah and prominent refugee sending country. Over the last two decades, South Africa has acceded to international refugee conventions and passed its own Refugees Act (no. 130 of 1998). In doing so, the post-Apartheid government eschewed some of the hallmarks of African asylum policies (e.g., camps, group determination, delegation of responsibility to UNHCR) ${ }^{4}$ relatively early on, opting for a self-settlement model of protection accompanied by individualized status determination procedures. ${ }^{5}$ The process of crafting the laws to define how this decision-making process would be administered was highly transparent and drew heavily on the expertise of, and inputs from, civil society and international non-governmental organizations. The result was a reception and status determination system containing strong procedural safeguards for applicants and a variety of institutional checks and balances on the decision-making process. These protections are buttressed by South Africa's progressive constitution and policed by a robust community of civil society monitors and legal service providers that possess considerable interest in migration issues, funding for projects around status determination and protection, and the capacity to demand compliance with the country's new refugee laws. ${ }^{6}$ In these respects, and on paper, South Africa stands out as a Global North-style status determination system, albeit located in the Global South.

Given the considerable promise of this nascent experiment in status determination, the current state of disarray in South Africa's refugee reception system is particularly concerning. South Africa possesses a large and growing back$\log$ of undetermined asylum claims. ${ }^{7}$ As is alluded to in the opening quotation, and will be documented in this piece, asylum seekers in South Africa experience extreme difficulties and trauma in the simple act of attempting to enter a refugee reception office and lodge their claim. Given the significant differences between these conditions and conditions at similar offices in Europe and North America it is worth beginning with a thick description drawn from Lawyers for Human Rights (LHR) monitoring at the Gauteng offices:

Rarely does an asylum seeker gain entry to a refugee reception office on their first attempt. The office accepts a limited number of applications per day. Entitlement to one of these positions is controlled by a hazy coalition of security guards, migrant agents, interpreters and officials who solicit bribes and favours in return for favourable treatment and employ oblique force against those who would challenge the integrity of their parallel system. Those who do not have the capacity to pay have a choice; well, a choice that is not really a choice. They can return at a later date and risk being caught by the police without documentation, or they can sleep overnight outside the office and retain their place in the official queue. On the nights when LHR did headcounts they discovered between 80 and 300 people sleeping outside the office. At night armed criminals visit the site. Incidents of theft are common. There have been several reports of rape. There is no shelter in the vicinity of the office and people often endure rain and very cold conditions while waiting outside. Women sleep with babies by their side. On some occasions the police have visited during the night and arrested asylum seekers or extorted them for bribes. Fights about places in the queue are common at night, sometimes degenerating into the throwing of bricks and stones and leading to several cases of hospitalisation. Efforts to normalise conditions of shelter outside the office have been resisted by officials. On at least one occasion the City of Tshwane arrived in the morning to clear all temporary shelters, bedding, and belongings of people gathered outside the office.

In the morning, people waiting outside begin to form themselves into queues. Agents, security guards and interpreters are heavily involved, making offers and explaining how people will be received on that day. No-one knows at this point how they will be received, who will be chosen and how many will gain entry. Sometimes it is elderly women, sometimes Malawians only, sometimes 40 , sometimes 100 . The police will arrive and on occasions make arrests. Sometimes people seek to flee the police and there have been at least two deaths caused by people attempting to escape, only to run headlong into the morning traffic. There will also be beatings; by the police, by security guards; on occasions by street vendors who join in. On one occasion at Rosettenville office, asylum seekers have been sprayed with water guns. On another occasion they were simply hosed down by a security guard. Almost everyone is in a heightened state of anxiety and there is invariably a great deal of pushing, shoving and then more fights, particularly when the gangs controlling entry pick people out of the queue or place their members at a privileged point in line. The new asylum seekers are soon joined by a steady stream of people waiting for renewals, who form something more closely resembling a queue. Since these people are only waiting for a stamp and not to fill in forms, they will usually all be served, though when they will be served varies, sometimes waiting for 2 hours, sometimes for 24 hours. All this occurs in a venue that reeks of urine and sweats with human anticipation and fear. All of this occurs before anyone has seen a Home Affairs official.

It is tempting to explain these problems in the reception system purely in terms of a mismatch between legal framework and geographic context. According to this line

(C) Darshan Vigneswaran, 2008. This open-access work is licensed under a Creative Commons Attribution-NonCommercial 4.0 International License, which permits use, reproduction and distribution in any medium for non-commercial purposes, provided the original author(s) are credited and the original publication in Refuge: Canada's Journal on Refugees is cited. 
of argument, individualized status determination models and Refugee Convention protection systems are not suited to Africa, where countries ordinarily experience conditions of mass influx from neighbouring countries and rarely possess the adequate bureaucratic resources or legal expertise to process these populations. This line of thinking is reflected in Toby Mendel's work on Tanzania, which ponders whether "it is time to recognise that the 1951 Convention is simply not the right instrument for poor countries hosting large numbers of refugees." "Various facets of refugee reception in South Africa support a similar assessment of conditions there. Over the past six years the country has consistently received over 30,000 applications for asylum per year. Given that these figures are produced by offices which set fixed quotas on the number of asylum claims received per day, the total number of asylum seekers entering the country is almost certainly higher. As the political and economic climate in Zimbabwe has deteriorated, hundreds of thousands of people from that country have been displaced across the border into South Africa, and at the time of writing it is highly plausible to suggest that more will come. Although the African National Congress (ANC) has passed a wide range of very progressive laws on a variety of human rights issues since taking government, lack of capacity and budget has meant that it has failed to deliver on many of its promises. Furthermore, the spread of corruption through the bureaucracy has consistently handicapped the government's ability to deliver essential services to desperately poor populations in the townships, let alone non-nationals in need. Many critics, including the members of the ANC leadership, have identified problems of capacity and corruption in the refugee reception system. ${ }^{9}$ The findings of this study support the idea that these characteristically "African" refugee governance problems have contributed to the dilapidated state of status determination processes in South Africa. Limited capacity and corruption do not, however, tell the whole story.

This study suggests that explaining conditions of access to status determination in South Africa requires us to pay more attention to the institutional culture of the government agency with primary responsibility for implementing refugee laws: the Department of Home Affairs (DHA). The study shows that, far from being simply the product of high demand or officials' predilection for with illicit remuneration, the barriers to asylum in South Africa are commonly produced by the individual effort of officials of the DHA, who act outside their legislative mandate to prevent asylum seekers gaining access to the reception system. While the methodology employed by this study does not allow for an explanation of precisely why officials behave in this manner, there is a range of evidence available from other archival, monitoring, and research work to generate a compelling hypothesis as to why this may be the case. This paper affords primary weight to the factor of institutional culture. Put simply, the DHA officials are embedded in an institution which sanctions its officials engaging in extralegal practices that prevent foreigners from entering and residing legally in South Africa. This culture, which has its roots in the DHA's Apartheid days, continues to inform how agents of the Department understand their responsibilities to new laws, and plays a considerable role in limiting access to asylum and undermining the integrity of the status determination system.

The paper will make this case in four parts. The first section outlines the principal characteristics of South Africa's refugee status determination system, paying specific attention to the key legislative responsibilities of the DHA. Section two introduces the methodology. Here, I explain why we chose to survey applicants at the reception offices. Section three analyzes the survey data and reveals the failure of the Department to meet its legal obligations. Section four attempts to explain these failures by looking at the institutional history of the DHA and some key events during the brief history of the administration of the Refugees Act. This section illustrates senior management's promotion of a culture of defensiveness towards asylum claims.

\section{South Africa's Status Determination System}

South Africa's refugee status determination system is the product of an ongoing and often ad hoc effort to respond to new refugee flows and commitments through an ongoing process of design, implementation, consultation, and reform. This process began with the signing of a series of agreements between 1991 and 1993 with the UNHCR and the government of Mozambique to create arrangements for the repatriation of Mozambican nationals who had fled the civil war in the late 1980s and early 1990s. After the transition to democratic rule in South Africa, the ANC government acceded to the OAU Convention (1995) and then to the United Nations Refugee Convention and its 1967 Protocol (1996). The Refugees Act was passed by Parliament in 1998 and, after some contestation of the terms of its implementing Regulations, came into effect in 2000. The details of the process leading to the passage of the Act have been dealt with elsewhere. ${ }^{10}$ For our purposes, it is important to note the progressive political context in which the government established its commitments to a refugee agenda. Many members of the ruling ANC had been hosted by neighbouring countries as exiles of Apartheid South Africa and had strong personal reasons to support a reciprocal policy. In this context, the objective of Mozambican repatriation and regularization, which occupied much of the early refugee policy-making debates, represented an opportunity to assist a faithful ally, and not simply afford protection to foreign nationals in need. Following this, 
the late 1990s represented an extremely progressive policymaking phase in South Africa for human rights. Not only did South Africa translate its Freedom Charter, with promises of protections for all living within its borders, into a new set of constitutional rights; it also signed up to a raft of international legislation on human rights and passed a wide range of domestic implementing laws. This spirit was not only reflected in the types of laws South Africa introduced, but extended to the way it designed new policy frameworks. The Refugees Act was drafted and passed through a series of consultative processes in which civil society representatives and consultants were heavily involved and their inputs often translated directly into statutory provisions and policy outcomes.

The principal outcome of this progressive policy-making process was a set of refugee laws which included a variety of procedural safeguards for asylum seekers. The refugee reception system envisaged in the legislation consists of four parts: entry, application, hearing, and documentation. Put simply, it is expected that an individual will register their intention to apply on entry; proceed directly to an office in the interior to make an application; and subsequently sit an interview with an official who will determine the claim; and it also is expected that the applicant will receive documentation validating their right to be in the country until the entire process is complete. The legislation and its regulations outline provisions to promote access to each stage of the status determination process. The first issue is the Act's protection of applicants' right to freely enter South Africa to make their claim. The legislation sets out a geographically bifurcated process whereby (a) applicants register their intention to apply for asylum either at their point of entry or first encounter with a government official; ${ }^{11}$ and (b) applicants formally lodge their applications in the country's interior. ${ }^{12}$ These provisions envisage a process whereby the various police, army, and ordinary DHA officials who man the border and border posts assume collective responsibility to ensure that new arrivals' intentions to make asylum claims are acknowledged. The DHA officials alone are responsible for issuing temporary permits and directing applicants towards sites where they can formally lodge a claim. The Act made specific provision for the establishment of refugee reception offices (RROs) for this latter purpose ${ }^{13}$ where officials must receive the asylum seeker's claim. ${ }^{14}$

The second set of provisions attempts to ensure that claims are made at the RROs in a free, transparent, and accurate manner. The DHA is responsible for ensuring that the RROs are staffed by trained Refugee Reception Officers ${ }^{15}$ who are responsible for:

- verbally notifying the applicant of their rights and obligations; ${ }^{16}$
- assisting applicants to properly complete their forms; ${ }^{17}$

- providing competent interpretation, where practicable and necessary; ${ }^{18}$ and

- ensuring the confidentiality of asylum applications and the information contained therein. ${ }^{19}$

The third set of provisions attempts to guarantee the fair adjudication of claims. Here, the legislation recognizes the limitations of an ordinary official's capacity to fairly apply refugee laws in all cases. The Refugees Act requires that the Refugee Reception Officer hand the application to a Refugee Status Determination Officer (RSDO). The RSDOs should be trained to determine status. ${ }^{20}$ These officers should formally interview all applicants, allowing for the presence of a lawyer if so desired, and determine whether to grant or reject refugee status. If an application is rejected, the applicant should be afforded the opportunity to appeal the decision to a higher authority. ${ }^{21}$ The DHA is obliged to establish a Standing Committee for Refugee Affairs and a Refugees Appeal Board to adjudicate on different categories of refusal. ${ }^{22}$

The fourth set of provisions provides for the temporary protection of applicants while their claims are decided. These provisions are crucial in South Africa, where the police zealously enforce immigration laws and documentation of an individual's status is crucial to prevent deportation and possible refoulement. When an applicant first registers their intention to apply for asylum they should be referred to a DHA official who should issue them with a "transit permit" verifying their right to be in the country for three weeks or until they formally lodge their claim. ${ }^{23}$ As soon as an individual lodges a claim, the Refugee Reception Officer should issue them with a temporary asylum seeker's permit. ${ }^{24}$ Refugee reception officers should also renew the asylum seeker's permit at regular intervals until a decision has been made and the applicant has exhausted all mechanisms of appeal.

To summarize, South African legislation requires the DHA to administer status determination in accordance with four linked provisions:

- settlement-oriented reception of claims to facilitate access;

- $\quad$ assistance by RROs to ensure free, transparent, and accurate completion of forms;

- interviews and appeal mechanisms to ensure fair adjudication of claims; and

- documentation to provide protection against refoulement.

\section{Methodology}

The DHA's failure to fulfill these and other procedural obligations has been rigorously documented over the years by a number of scholarly publications and NGO reports. ${ }^{25}$ 
However, these reports have been primarily based upon qualitative data, including (a) interviews with asylum seekers, policymakers, and service providers; (b) observations of practices at the RROs and at the border; and (c) reports and statements by public officials and public bodies such as the Refugee Directorate, the Standing Committee for Refugee Affairs, and the Parliamentary Portfolio Committee for Home Affairs. This data has been very useful in developing assessments of key problem areas in departmental performance. It has also been helped analysts to generate plausible hypotheses as to why the DHA has been unable to fulfill these obligations. However, this data can not help us identify the seriousness of the various implementation failures identified or measure the power of the various competing explanations of access problems.

In order to account for these shortfalls, gauge to what extent the DHA was fulfilling each of these four of these procedural requirements, and discriminate between competing plausible explanations of the shortfalls, we have used a survey of asylum-seeker experiences. This survey began with an exhaustive study of governmental and non-governmental monitoring of the RROs to identify a series of performance benchmarks for the DHA in relation to reception, assistance, interviewing, and documentation. We used these benchmarks to design an instrument that would test whether the recollected experiences of asylum applicants met the minimum standards set out in the relevant legislation. The majority of the questions were closed-ended, though in order to develop a clearer idea about (a) illegal and conflict-related activities and (b) applicants' perceptions and personal understanding of the asylum-seeker process, we also asked a small number of open-ended questions. The instrument was refined through:

- a series of workshops with lawyers and other civil society partners in Johannesburg, Durban, and Cape Town to ensure national relevance and comparability; and

- $\quad$ piloting at the Pretoria and Cape Town offices.

The instrument was then translated into French, Shona, and Kiswahili and back-translated to English to check translation accuracy.

Given the often lengthy periods that pass between first applying for asylum and first sitting an interview, and the potential for loss of accurate recall, it was decided to split the survey into two parts and target two separate populations. The target population for the first survey was all applicants who had submitted an application for asylum but had yet to sit a formal interview with an RSDO (hereafter: pre-RSDO). The target population for the second survey was all applicants who had sat an interview with an RSDO (hereafter: post-RSDO). Given the difficulties in generating household and telephonic surveys of asylum seekers in South Africa, ${ }^{26}$ and in securing interviews with applicants leaving the RRO, it was decided to sample applicants waiting to renew their asylum-seeker permits. A sample size of 400 applicants per city was chosen (200 pre-RSDO, 200 post-RSDO). These subjects were systematically selected over a one-month period in November and December 2007. Due to language difficulties and subjects' security concerns, Somalis, Ethiopians, Bangladeshis, and Pakistanis were under-represented. Given current trends in the flows of asylum seekers into the country, it is relatively unsurprising that most respondents were male and either of Zimbabwean or Congolese nationality. The current paper reviews findings from the survey conducted at the Gauteng-based offices.

\section{Evaluating DHA Performance}

Supporting the findings of previous monitoring and analysis, the survey reveals a refugee-reception system that is not functioning as intended by the legislation. In part this is due to problems of capacity. The Refugee Affairs Directorate itself acknowledges its inability to adequately process the number of claims received on an annual basis. This reflects a consensus position of all stakeholders, including the DHA Minister, senior-level DHA officials, the Parliamentary Portfolio Committee, judges adjudicating on refugee and asylum matters, and refugee advocates. More important are the specific findings regarding the obstructive institutional culture behind these problems. Whereas previous monitoring had suggested rampant corruption and/or laxity of officials in enforcing laws as potential problems, the current study suggests that officials generally err on the side of overzealousness in the administration of status determination procedures, unlawfully denying access to the system and negatively prejudicing applicants' claims. The following discussion will support this claim through a discussion of the four legislative provisions outlined above.

\section{Free-settlement Oriented Access}

The overzealous enforcement of immigration laws means that asylum seekers are rarely able to register their intention to claim asylum. The prototypical applicant at the Pretoria office enters the country without any identifying documentation $(53 \% \mathrm{n}=226)$, informally $(58 \% \mathrm{n}=223)$, across a Zimbabwean border $(78 \% \mathrm{n}=227)$. Hence, even though the Refugees Act specifically caters for informal entrants, this means that applicants who do not enter at a border post will rarely be able to register their intention to claim asylum. The security officials (police and army) they are most likely to first encounter in the Limpopo border region have a limited working knowledge of South African asylum laws and regularly deport Zimbabwean 
Figure 1: Entered RSA through an official border post

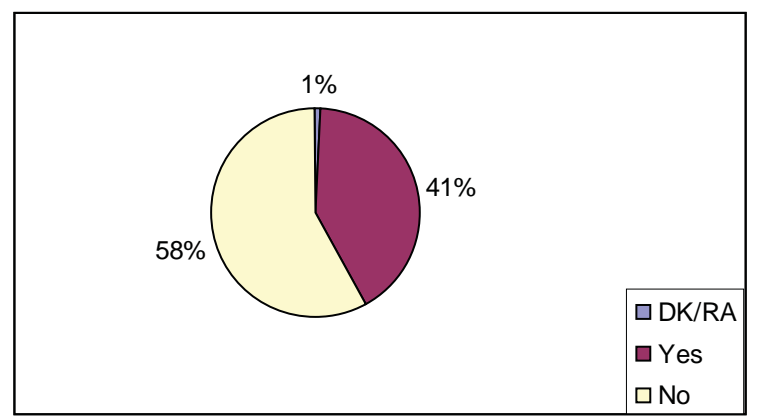

nationals (the majority of entrants) without calling upon the DHA to conduct status determination.

Asylum seekers who enter South Africa through a border post are better off than informal entrants because they can register a claim for asylum as soon as they meet a DHA official. However, DHA officials commonly deny applicants the right to register their intention to apply. The fact that onefifth of applicants who were eventually able to obtain their asylum papers noted that they were not given a permit when they informed officials at the border of their intention to apply $(20 \% \mathrm{n}=30)$ suggests that a much larger proportion of those who have tried never reached the office. It is also likely that many potential applicants do not think it is worth trying to register their claim at the border. Given the unstated policy of denying Zimbabwean migrants the right to asylum at the Beitbridge border post, only one-fifth registered a claim upon entry $(19 \% \mathrm{n}=79)$. In addition to individual officials pro-actively creating barriers to entry, DHA officials do little to ensure that potential applicants are notified of their rights to register their claims. One in ten $(10 \% \mathrm{n}=230)$ applicants found out that they needed to make their claim for asylum at an RRO. The majority were told by friends or family ( $72 \%$ $\mathrm{n}=230$ )

Given these factors, the majority $(90 \% \mathrm{n}=232)$ of applicants arrive at the reception office to formally lodge their claim without having previously registered their intention to do so. At this stage they encounter further barriers to access. The main problems are the quotas each office has instituted in order to limit the number of applications per day. ${ }^{27}$ These quotas, which directly contravene the statutory obligation to receive claims, result in extremely long queues. Our findings show that an average applicant will have to return to the RRO approximately three times, and wait approximately twentytwo days between first arriving at the office and first entering the office. Such findings may be taken to reflect an unavoidable consequence of officials' attempts to match their limited capacity to receive applications with an overwhelming demand for asylum. This interpretation becomes less plaus- ible when we reflect upon the types of conditions applicants are forced to endure in the line. Most $(60 \% \mathrm{n}=231)$ spend at least one night outside to maintain their position in the queue. On average, those who spent one night could expect to spend ten nights outside-about one of every six $(18 \% \mathrm{n}=$ 141) doing so with children in their care. The line itself is a site where asylum seekers, many of them already victimized and brutalized in their countries of origin, become targets once again. About one-third of respondents $(35 \% \mathrm{n}=226)$ reported being hurt, threatened, or robbed whilst waiting in the queue. The accompanying box offers their accounts of such experience.

\section{Question: Did anyone hurt you, threaten you, or steal your belongings while you were waiting in line? Can you explain what happened?}

"I was sleeping and I woke up in the morning and I did not find my money or my phone."

"It was these two guys who threatened me; they threw me out of line and took my phone and money-two hundred rand."

"People crush on you in the line and I was hurt because I was defending my child."

"Someone wanted to fight with me; those who control the queue; wanted me to pay. I didn't have any money."

"The time I was at the surrounding area of the reception my clothes and belongings were taken by the Metro Police."

"We were hit by stones by passers-by during the night."

It is difficult to directly link this evidence of neglect to an explanation of DHA official behaviour; however, it is certainly cause to reconsider whether the decision to limit the number of entries is purely the result of capacity issues, or rather a more intentioned barrier to access. After all, DHA reception officials, regardless of their rank, witness the suffering of people in the queue every day when they come to work. These doubts become more compelling when considered in relation to the apparent lack of attention that officials give to ensuring that those who enter are able to lodge their claims. Having endured the queue, many respondents are given forms to fill out and told to return on a later date $(34 \% \mathrm{n}=230)$, or given an appointment for another date $(15 \% \mathrm{n}=230)$. Some wait without being given any attention at all $(3 \% \mathrm{n}=230)$. Since long queues to access do not appear to accord with an effort to ensure that those who enter are served correctly, one might be tempted to assume that they are the conscious product of corrupt officials. At least one study on the South African border suggests that long queues are often purposely created and sustained by corrupt officials who wish to generate demand for illegal services to circumvent the line. ${ }^{28}$ Our results cast doubt on a similar reading of 
refugee reception. While a significant number of respondents reported having paid someone to get their papers $(10 \%$ $\mathrm{n}=230$ ), doing so did not significantly impact upon the time it took to lodge a claim.

\section{Assisting Completion of Forms}

Perhaps officials are simply lazy and not motivated by any specific desire to create barriers to the lodging of claims? Some of our findings on the assistance applicants received inside the office might support such a reading. Almost twothirds $(68 \% \mathrm{n}=219)$ of respondents report that officials provided no assistance in completing the form. A similar proportion $(67 \% n=218)$ report that officials did not go over the form with them once it was complete. Officials only provided assistance to a small number $(17 \% \mathrm{n}=70)$ of those who needed interpreters. When officials did pay attention to a case, they usually did so in a manner that would jeopardize the confidentiality of the claim. Applicants were often questioned in a public area-more than a quarter $(28 \%)$ of the 129 applicants who were asked questions by officials about their asylum claim said that other people were able to overhear their answers.

Further analysis of this data offers a more worrying finding: of officials purposively negatively prejudicing claims. While officials clearly explain to applicants what their obligations are, the same is not true of applicants' rights. Most $(92 \% \mathrm{n}=$ 228) applicants reported that they were aware of their obligation to renew their permit before it expired. In contrast, very few $(8 \% \mathrm{n}=228)$ reported being told they were allowed to bring a lawyer to their next interview. Furthermore, most $(63 \% \mathrm{n}=228)$ were not aware that their answers would not be shared with anyone outside the office. Going beyond simply preventing applicants from knowing their rights, there is some evidence to suggest that officials arbitrarily intervene in the filling out of forms. The respondents who most needed assistance (respondents who needed interpreters and respondents who had difficulties understanding the questions on the form) were less likely to receive assistance than those who needed no help.

\section{Ensuring Fair Adjudication}

The tendency to negatively prejudice applications extends to the status determination process itself. In some respects we simply see a recurrence of the same problems of laxity in official performance of duties that plague the reception of applications. Officials do not provide interpreters when they are needed and do not inform applicants of rights that will potentially improve their capacity to accurately tell their story, such as the right of female applicants to request an interviewer of the same sex. Perhaps more importantly, official practices put applicants in a position where they are unlikely to be able to accurately recount or defend their stories. Most (62\% $\mathrm{n}=197$ ) applicants say they were given no advance warning that they would be interviewed. This is because reception officers commonly neglect their duty to clearly schedule dates for each applicant's interview, preferring instead to select individuals for an interview from the line of applicants waiting to renew their permits. After having waited for months and in some cases years for the interview, the individual is not likely to be in a position to refuse. Given this, it is relatively unsurprising that most $(88 \% \mathrm{n}=196)$ applicants note having brought no evidence to the interview to substantiate their case. Most applicants do not receive a copy of their original application form. Again, there may be some reason to attribute the above problems to lack of capacity or sheer laziness. The DHA has notoriously bad information technology and case flow management systems. This often goes as far as not having working photocopiers or not having adequate paper to print identification documents. ${ }^{29}$ Due primarily to the unwillingness of staff to adopt new information technology systems, ${ }^{30}$ there is no centralized database of applications and no ability to track whether the applicant has left the province to make a claim elsewhere.

Again, the incompetence of officials does not account for all of the shortfalls. While some sins of omission can be easily dismissed as the result of absent-mindedness, laziness, or incompetence, the failure of officials to make simple concessions during official hearings suggests a more intentioned effort to deny applicants the capacity to compensate for their lack of preparation. Most officials do not begin the interview by explaining to the applicant the purpose of the interview. This is a significant problem because the applicant has already been caught by surprise and may think they are being interrogated for having not fulfilled one of their obligations (e.g. to maintain a valid permit or to uphold South African laws). Although an RSDO will usually possess a copy of the applicant's original application form, most $(66 \% \mathrm{n}=191)$ applicants are not provided with a chance to view this copy before the interview. Furthermore, most applicants told us that the RSDO did not go through their form with them $(72 \% \mathrm{n}=$ 194). Given that in most cases the RSDO will refer primarily to the contents of the application form and in many cases identify problems on the form, or question the veracity of an individual's story, these omissions place the applicant at a considerable disadvantage, denying them the ability to know with any certainty the reasons why they are being asked various questions.

\section{Providing Protecting Documentation}

The final obligation of the reception officials is to ensure that applicants are provided with adequate documentation to legalize their stay in the country. As we have already noted, 
officials are generally lax in ensuring that all applicants' claims are formally lodged on the same day they enter. As a result, a minority of applicants $(41 \% n=230)$ receive this permit on the first day they enter the office. On average, asylum seekers wait a further five days after first entering the office before they finally receive a permit.

Figure 2: Got permit the first time entered the Refugee Reception Office

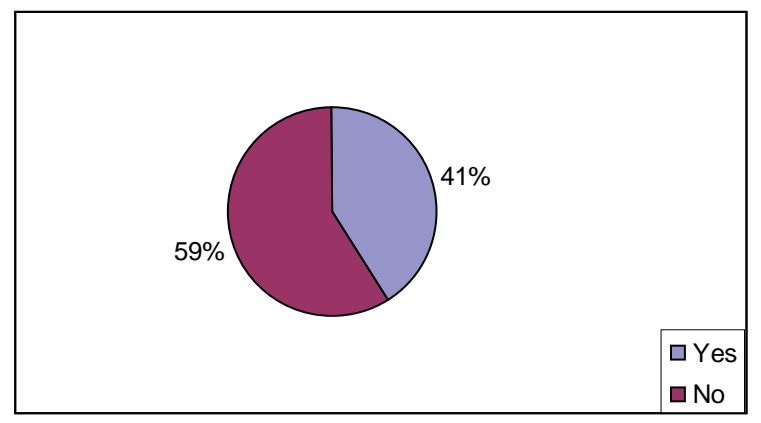

This general sloppiness extends to the process of issuing permits where almost a quarter of respondents $(24 \% \mathrm{n}=$ 229) reported mistakes on their original permits, among them misspelled or incorrectly ordered names and incorrect birthdates.

Given the frequency with which applicants are stopped and asked for their papers, the scrutiny which police officers commonly apply to asylum permits, and the potential risks they face of being subject to refoulement, it is difficult to accept these mistakes as mere laxity and more tempting to assess them as the product of a more "malign indifference." This reading is buttressed by our data on the problems applicants experience in maintaining their documentation. An average asylum seeker has to renew his or her permit five times a year and will come to the RRO more than once to have it renewed. Legislation does not prescribe the validity period for asylum permits, so it is uncertain why officials, given the freedom to use their discretion, continue to specify, on average, validity periods of two-and-a-half months on permits. This practice increases office workloads in the processing of renewals, while promoting the social exclusion of already vulnerable migrants who must regularly sacrifice work hours and transport funds in order to remain legal. Some asylum seekers $(13 \% \mathrm{n}=217)$ fail to renew their permits in time due to work or personal commitments that prevent them from coming to the office, and a small percentage $(5 \% \mathrm{n}=205)$ report having been arrested or fined for having an expired permit.

\section{Summary}

In summary, the findings of this survey suggest that South Africa's RROs commonly fail to meet the basic procedural obligations that lawmakers designed to ensure fair and free access to the status determination process. In some respects the study simply extends some common indictments of South African governance in the post-Apartheid era, and post-colonial governance in Southern Africa more generally, to the field of refugee affairs. Like counterparts in other areas of government, the Refugee Directorate in the DHA appears to lack the capacity to fulfill South Africa's newly progressive laws. It is unable to ensure that migrants seeking protection can lodge their claims, access documentation, and receive fair adjudication. Furthermore, the DHA appears to lack the ability to effectively manage and discipline its junior officials. Laxity, incompetence, and to a lesser extent corruption create unnecessary blockages in the system and jeopardize the rights of claimants.

The findings of this survey also depart in significant ways from this general acceptance that difficulties in Africa in administering individual-based status determination stem simply from the fact that states are weak, fragmented, and corrupt. Several of the instances of procedural breakdown uncovered by this study suggest that officials were not simply failing to do their jobs, but were collectively going out of their way to repel, hinder, and undermine asylum seekers' capacity to receive fairly adjudicated claims. Officials (a) refused to register or receive intentions to apply, thereby subjecting applicants to various forms of hardship; (b) interfered without warrant in the preparation of application forms; (c) kept applicants "in the dark" during interviews; and (d) imposed conditions to make it difficult to maintain valid identity documents. This behaviour poses an interesting puzzle for further analysis. Why would ordinary officials seek to obstruct asylum seeker claims in this way? Unfortunately, our survey instrument, which was specifically designed to capture asylum-seeker experiences, is not capable of providing a compelling account of officials' motivations. Ultimately, it is highly unlikely that these questions can be solved without ethnographic analysis of official culture within the DHA itself. In the absence of such data, I will attempt to piece together a plausible hypothesis. The rudiments of this explanation can be found in the historical origins of the DHA and the decisions made by the Refugee Directorate at key moments since its incorporation. The essence of the argument I want to put forward is that the obstructionist behaviour of DHA officials is an expression of a discretionary institutional culture that has become defined by the objective of excluding undocumented migrants.

\section{What Do We Make of Bureaucratic Obstructionism?}

In my other writing on this subject I have emphasized the historic lack of capacity within the DHA. ${ }^{31}$ However, in 
addition to its many capacity constraints, the DHA has been historically characterized by an institutional culture which significantly hampers its ability to adequately administer the Refugees Act. While indifference and impunity can be the hallmarks of almost any government bureaucracy, ${ }^{32}$ and were common features of Apartheid era official attitudes, ${ }^{33}$ the immigration activities of DHA officials have been uniquely structured by legislation which fostered such an attitude towards clients. Immigration laws during the Apartheid era, which were brought together underneath a single Aliens Control Act in 1991, provided officials with a considerable degree of discretion to decide how individual requests for immigration permits ought to be evaluated. As suggested by the former special advisor to the Minister, the purpose of this highly discretionary environment was to validate racially prejudicial outcomes in the language of non-racial administrative law:

If you read the Aliens Control Act and you're applying for a permit, you do not know under what criteria you will get or you will not get the permit. You will not know what procedures you would need to follow. The Aliens Control Act gives no information in terms of which most of the permit categories would qualify for either permanent or temporary residency. In terms of permanent residence, there was a mechanism in place where ... an application would come in under some general criteria of being a good citizen and somehow in the application of those criteria whatever came out were white, Anglo-Saxon, protestant people. ${ }^{34}$

Importantly, while the new administration has subsequently passed legislation that was specifically intended to reduce the degree of discretion available to individual officials, the Refugee Directorate officials began to administer refugee laws in the context of the Aliens Control Act. ${ }^{35}$ Furthermore, training has yet to transform the way in which officials administer the laws. This has been specifically acknowledged by the current Home Affairs Minister, Nosiviwe Mapisa-Nqakula:

[i]t is sometimes very difficult to get officials to change their mindsets. It seems that many officials are still stuck in the era of the Aliens Control Act. Some seem to think that the law means what they think it should mean. ${ }^{36}$

While clearly acknowledging the origins of the problem, the Minister's comments do not recognize the significance of subsequent government policy in ensuring that official discretion was utilized to restrict entry, instead of being deployed for personal gain or avoidance of duty. Why is it that officials appear to go out of their way, and beyond the law, to prevent access to asylum?

The origins of this answer can be found in the generally restrictive discourse towards undocumented migrants that has been formulated within the DHA since the transition to democracy. Within the Government of National Unity, the leader of the Inkatha Freedom Party, Mangosuthu Buthelezi, identified illegal immigration as a pressing threat to South Africa's hopes of economic upliftment for the majority of its previously disenfranchised and poverty-stricken population. His ideas live on in the current administration, and particularly within the DHA Ministry, which has sought to ensure that migrants of various forms were not able to enter South African territory and, barring that, the South African labour market. This ideology also found expression in South Africa's new Immigration Act, ${ }^{37}$ which set out a series of provisions excluding all those who would compete with South Africans for jobs and/or could not contribute to the development of South African skills or directly employ South Africans. However, it has also found deeper expression in the world views of officials within the DHA, who conceptualize the prevention of immigration as a responsibility that goes beyond their legally mandated role of ensuring the sanctity of South Africa's immigration laws.

Evidence of this abiding commitment to an exclusionary ideology can be found in the efforts of the reception officials to limit access to asylum. The first such instance occurred in 2001 when, in an apparent effort to instil the "jobs-protecting" ethos of the forthcoming immigration legislation into the refugee system, the then Minister of Home Affairs, Mangosuthu Buthelezi, authorized the production of an asylum-seeker permit which expressly prohibited asylum seekers from working or studying, as one of the conditions of their temporary stay in the Republic. The DHA position was summed up in the minutes of the Standing Committee Meeting confirming the decision to prohibit work and study rights:

it happens that a person comes to our country to apply for asylum while he in fact is looking for a job ... this was the main cause of the backlog that is now troubling the department. ${ }^{38}$

In the early years of refugee protection, the Department was already experiencing a considerable backlog of undetermined applications. This meant that asylum seekers would reside legally in South Africa for months and often years without any legal means of earning a living. This issue was brought to a head in the case of Watchenuka. ${ }^{39}$ While accepting that foreign nationals did not have the right to freedom of trade, occupation, or profession provided for in section 22 of the Constitution, the complainant argued that rights 
to life, dignity, equality, and administrative justice do apply to foreign nationals and that the denial of the right to work in effect contravened these constitutional rights. Although the presiding judge did not rule on the constitutionality of the prohibitions, he declared the prohibition "inconsistent" on the grounds that the decision had not been made in accordance with the appropriate procedure, i.e. with adequate consultation with the Standing Committee for Refugee Affairs. The Watchenuka case is crucial because it provides us with the first evidence of the Ministry's discomfort at the inconsistencies between refugee protection laws and immigration policies. It also evinces a willingness on the part of high-level officials, and in this case the Minister, to avoid their procedural obligations to refugee protection in order to privilege the goal of exclusion.

This dynamic would resurface in the 2006 case of Tafira ${ }^{40}$ when the DHA sought to deny access to applicants it deemed to be unworthy or not bona fide. By this time, some of the problems identified above in gaining access to the RROs had surfaced. Applicants were waiting in long queues, and the DHA was unable to receive applications from all those presenting themselves at the offices. In order to deal with this problem the Refugee Directorate introduced a "prescreening" system for all applicants. This process required applicants to complete an additional form, prior to formally lodging their application. The form was not contemplated in either the Refugees Act or its Regulations, and varied in content between different offices, asking applicants to respond to a series of questions about their reasons for applying. DHA officials would use the forms to identify the likelihood of success of a claim and decide on that basis whether to allow an individual to make a formal application. Applicants deemed to be unlikely to be successful claimants would be issued with instructions to apply for a work permit or other form of residential permit at an alternative DHA office. On some occasions the DHA went further to initiate procedures for deportation of pre-screened applicants. In Tafira, the court ruled in favour of the WITS Law Clinic that the pre-screening system was illegal.

While no longer formally practiced at the reception offices, the pre-screening case is crucial because it evinces the support of upper-level management within the DHA for procedures that protect South African borders, regardless of their conformity with the provisions of the Refugees Act. Importantly, and despite the considerable evidence that backlogs, delays, and poor service delivery have been characteristics of South African status determination since the mid1990s, the DHA has not only argued in favour of its rights to restrict access, but has turned the argument on its head, justifying additional restrictions by blaming the current problems at the RROs on the asylum-seeker population as a whole. In communication with Lawyers for Human Rights, DHA officials indicated that "they were acting in accordance with the Department's policy of identifying asylum seekers who, in their opinion, would not qualify for asylum while queuing to make their asylum applications." ${ }^{\prime 1}$ The Department conceded that it had instituted a queue management system requiring immigration officers to enquire from the people in the queues about the purpose of their visit to the offices because "in many instances the queues are congested by foreigners who queue for immigration permits or reasons other than application for asylum." 42 If such persons were not in possession of proper documentation they would be considered "illegal foreigners" and arrested.

These examples do not provide us with conclusive evidence on the motivations of ordinary DHA officials. However, they collectively point to the existence of an official attitude or mindset within the DHA that condones, or at least enables, the types of status determination processes we saw in the previous section. Across these cases we see officials seeking to move beyond the mandated procedures and in some cases in direct defiance of refugee law in order to ensure that the integrity of the South African immigration regime is sustained. These measures suggest the possible presence within the DHA of an institutional culture that endorses illegal actions which ensure that potential applicants are excluded. While these various forms of obstruction have been represented by the Department as ways of ensuring the sanctity of the reception system, it is important to note that neither of these moves can ensure that the ostensible targets of protection, so-called bona fide asylum seekers are guaranteed access. Instead, working with a logic similar to that of immigration laws, policy makers have sought to utilize deterrence and in some cases deportation to repel a variety of potential applicants from the reception system. It seems plausible to suggest that when junior officials within the Department act with the same sort of impunity towards their own official obligations, their actions are more likely to be endorsed than sanctioned by their seniors.

\section{Concluding Remarks}

This paper has developed the foundations for an intriguing debate on status determination across the divides of the Global North and the Global South. By holding up the ambitious procedural commitments of the South African government to the scrutiny of a "customer survey" we have exposed the range and depths of problems within the reception system. Previous analyses of this system have relied heavily on observations at the offices or anecdotal reports and have therefore been limited in terms of their ability to explore the relative merits of competing diagnoses of the limitations of applied status determination law. Although limited to a sin- 
gle and possibly somewhat atypical case, the findings of this study ask us to entertain the possibility that the implementation problems in South Africa may not merely reflect the conventional story of state failure so familiar to the politics of development and so commonly witnessed in sub-Saharan Africa. Rather, the image of officials going out of their way to create barriers to asylum suggests the existence of an institutional culture that repeatedly undermines the efforts of monitors and other external bodies to implement reform. Using evidence of official policy I then argued that these activities constitute outcomes of an institutional culture of immigration protectionism that is prevalent within the DHA.

If we accept this interpretation, then we are forced to go beyond dismissing the experiences of asylum seekers in South Africa as the inevitable malaise of status determination in a developing country. Instead, we are compelled to think of the facets of institutional culture, including humanitarianism, multi-culturalism, liberalism, and a human rights ethos on the one hand, and xenophobia, racism, mis-directed patriotism, and protectionism on the other, that may influence the manner in which status determination systems function in other, non-African settings. In particular, the relatively rapid deterioration of South Africa's protection regime forces us to consider the long-term negative consequences of the current anti-asylum-seeker consensus in developed countries for the capacity of states to protect refugees.

\section{Notes}

1. Anonymous asylum seeker outside the Pretoria Refugee Reception Office.

2. Bonaventure Rutinwa, "The End of Asylum? The Changing Nature of Refugee Policies in Africa," Refugee Survey Quarterly 21, no. 1/2 (2002): 12-41.

3. Eduardo Arboleda, "Refugee Definition in Africa and Latin America: The Lessons of Pragmatism," International Journal of Refugee Law 3, no. 2 (1991): 185-207; M.R. Rwelamira, "Two Decades of the 1969 OAU Convention Governing the Specific Aspects of the Refugee Problem in Africa," International Journal of Refugee Law 1, no. 4 (1989): 557-561.

4. Jennifer Hyndman and Bo Viktor Nylund, "UNHCR and the Status of Prima Facie Refugees in Kenya," International Journal of Refugee Law 10 (1998): 21-48; Loren B. Landau, The Humanitarian Hangover: Displacement, Aid, and Transformation in Western Tanzania (Johannesburg: Witwatersrand University Press Publications, 2008); Toby D. Mendel, "Refugee Law and Practice in Tanzania," International Journal of Refugee Law 9, no. 1 (1997): 35-59; George Mukundi Wachira, "Refugee Status Determination in Kenya and Egypt" (LL.M. thesis, University of Pretoria, 2003).

5. Jonathan Klaaren and Chris Sprigman, "Refugee Status Determination Procedures in South African Law," in Advan- cing Refugee Protection in South Africa, ed. Jeff Handmaker, Lee Anne de la Hunt, and Jonathan Klaaren (New York: Berghahn, 2008).

6. Ingrid Palmary, "Recommendations on Atlantic Philanthropies' Funding for the Migration and Human Rights Sector: Priorities, Gaps and Weaknesses in the Sector" (report prepared for Atlantic Philanthropies, 2006) [unpublished].

7. Jeff Handmaker, "Starting with a Clean Slate? Efforts to Deal with Asylum Application Backlogs in South Africa," in Advancing Refugee Protection in South Africa (see note 5); : 1-29.

8. Mendel, "Refugee Law and Practice in Tanzania," 59.

9. Consortium for Refugees and Migrants in South Africa, "Protecting Refugees and Asylum Seekers in South Africa" (2007); Department of Home Affairs, Final Report on the Support Intervention in the Department of Home Affairs (Parliamentary Monitoring Group, 2007), <http:// www.pmg.org.za/docs/2007/070314report.htm> (accessed 5 May 2007); Fever Tree Consulting and A.T. Kearney, "Transforming the Department of Home Affairs: Refugee Affairs: Reception Offices Network Integrated Plan Workstream Delivarables \#7” (2007); Forced Migration Studies Programme, WITS Law Clinic, and Lawyers for Human Rights, "Crossing Borders, Accessing Rights, and Detention: Asylum and Refugee Protection in South Africa" (2006); IQ Business Group, "Report on the Process Engineering Findings and Recommendations Related to the Processing and Adjudication of Applications for Asylum Received by Refugee Reception Offices" (2006).

10. Florencia Maria Belvedere, "Beyond Xenophobia: Contested Identities and the Politics of Refugees in Post-Apartheid South Africa" (Ph.D. dissertation, University of Minnesota, 2006); Jeff Handmaker, Lee Anne de la Hunt, and Jonathan Klaaren, eds., Advancing Refugee Protection in South Africa (New York: Berghahn, 2008); Timothy R. Smith, "The Making of the 1998 Refugees Act: Consultation, Compromise, and Controversy" (Working Paper no. 5, Forced Migration Studies Programme, 2003), <http://www.migration.org. $\mathrm{za} />$ (accessed 10 June 2008).

11. Refugees Act Regulations, s. 2(2).

12. Refugees Act, s. 21; Refugees Act Regulations, s. 2(1).

13. Refugees Act, s. 8.

14. Ibid., s. 21(2)(b).

15. Ibid., s. $8(2,3)$.

16. Refugees Act Regulations, s. 5 .

17. Refugees Act, s. 21(5).

18. Refugees Act Regulations, s. 5.

19. Refugees Act, s. 21(5).

20. Ibid., s. $8(2,3)$.

21. Ibid., s. 24; Refugees Act Regulations s. 10

22. Refugees Act ss. 9-20, 25-6; Refugees Act Regulations, ss. $13-4$.

23. Immigration Act, s. 23.

24. Refugees Act, s. 22; Refugees Act Regulations, s. 13. 
25. Consortium for Refugees and Migrants in South Africa, "Protecting Refugees and Asylum Seekers in South Africa;" Lee Anne de la Hunt and William Kerfoot, "Due Process in Ayslum Determination in South Africa from a Practitioner's Perspective: Difficulties Encountered in the Interpretation, Application and Administration of the Refugees Act," in Advancing Refugee Protection in South Africa (see note 5); Department of Home Affairs, Final Report on the Support Intervention in the Department of Home Affairs; Forced Migration Studies Programme, WITS Law Clinic, and Lawyers for Human Rights, "Crossing Borders, Accessing Rights, and Detention: Asylum and Refugee Protection in South Africa;" IQ Business Group, "Report on the Process Engineering Findings and Recommendations Related to the Processing and Adjudication of Applications for Asylum Received by Refugee Reception Offices;" University of Cape Town Law Clinic, "Final Report of the Uct Observation Team on the Challenges Facing the Cape Town Refugee Reception Office" (2007).

26. Darshan Vigneswaran, Lost in Space: Residential Sampling and Johannesburg's Forced Migrants (Forced Migration Studies Programme Migration Methods and Field Notes, n. 4, 2007), <http://www.migration.org.za/> (accessed 10 June 2008).

27. At some offices this involves setting an absolute maximum on the total number of cases. Other offices will set more quotas on the number of applicants per nationality or set aside specific days to receive applicants from various countries.

28. David B. Coplan, "A River Runs through It: The Meaning of the Lesotho-Free State Border," African Affairs 100 (2001): 82-116.

29. Department of Home Affairs, Final Report on the Support Intervention in the Department of Home Affairs.

30. IQ Business Group, "Report on the Process Engineering Findings and Recommendations Related to the Processing and Adjudication of Applications for Asylum Received by Refugee Reception Offices."

31. Darshan Vigneswaran, "Enduring Territoriality: South African Immigration Control," Political Geography 27 (2008): 783-801.

32. Josiah Heyman, "Putting Power in the Anthropology of Bureaucracy: The Immigration and Naturalization Service at the Mexico-United States Border," Current Anthropology 36 (1995): 261-287.

33. De la Hunt and Kerfoot, "Due Process in Ayslum Determination in South Africa from a Practitioner's Perspective: Difficulties Encountered in the Interpretation, Application and Administration of the Refugees Act."

34. Interview of Mario Ambrosini, former Special Advisor to the Minister for Home Affairs (22 September 2006) [unpublished; digital recording on file with author].

35. Klaaren and Sprigman, "Refugee Status Determination Procedures in South African Law."

36. Department of Home Affairs, Briefing by the Minister of Home Affairs, Mrs N. Mapisa-Nqakula to the Chambers of Commerce and Stakeholders from Business Community (Department of Home Affairs, 2006), <http://www.homeaffairs.gov.za> (accessed 10 June 2008).

37. n. 13 of 2002.

38. Standing Committee for Refugee Affairs, "Minutes of Meeting of the Standing Committee, 18 September," ed. Department of Home Affairs (2000).

39. Watchenuka v. Minister of Home Affairs [2002] JOL 10388.

40. Tafira v. Minister of Home Affairs [2002] JOL 12960,

41. Lawyers for Human Rights, 31 March 2005.

42. Ibid.

Darshan Vigneswaran is a Senior Researcher at the Forced Migration Studies Programme, University of the Witwatersrand, South Africa. His research interests are in international relations, political geography, international migration, and research methods. The author would like to thank Roni Amit, Tesfalem Araia, Veronique Gindrey, Tobias Hlalambelo, Loren Landau, and Tamlyn Monson for their assistance and for comments on previous drafts. Atlantic Philanthropies and the British Academy UK-Africa Fellowship scheme provided support for research and writing up respectively. The study would not have been possible without the generous assistance of the Department of Home Affairs, Lawyers for Human Rights, UCT Law Clinic, and WITS Law Clinic. 